\title{
Conexões
}

\section{Corporeidade e fenomenologia: o corpo vivo e o corpo vivido de Petrucia Nóbrega}

\author{
Arliene Stephanie Menezes Pereira ${ }^{1}$
} Daniel Pinto Gomes ${ }^{2}$

\section{RESUMO}

O presente texto apresenta a entrevista com a Professora Dra. Terezinha Petrúcia da Nóbrega, realizada em 03 de novembro de 2017 às 19:20 em Fortaleza, Ceará. A professora nos conta sobre sua trajetória acadêmica e suas aproximações com o pensamento da fenomenologia de Merleau-Ponty. Relata sobre algumas de suas obras, e suas experiências com o autor Bernard Andrieu na praia da Tambaba. Por fim nos faz um breve relato sobre sua visão acerca de uma educação sensível.

Palavras-Chave: Corpo. Fenomenologia. Corporeidade. Entrevista. Petrúcia Nobrega.

\footnotetext{
${ }^{1}$ Universidade Federal do Rio Grande do Norte

${ }^{2}$ Universidade Federal do Ceará

Recebido em: 23 fev 2018

Aprovado em: 19 maio 2018

Contato: stephanie_ce@hotmail.com
} 


\section{Corporeity and phenomenology: the living body and the lived body of Petrucia Nóbrega}

\section{ABstract}

This text presents the interview with Professor Terezinha Petrúcia da Nóbrega, held on November 3, 2017 at 7:20 pm in Fortaleza, Ceará. The teacher tells us about her academic trajectory and her approximations with the thought of Merleau-Ponty's phenomenology. He reports on some of his works, and his experiences with author Bernard Andrieu on Tambaba Beach. Finally he gives us a brief account of his view of a sensitive education.

Keywords: Body. Phenomenology. Corporeity. Interview. Petrúcia Nobrega.

\section{Corporeidad y fenomenología: el cuerpo vivo y vivido de Petrucia Nóbrega}

\section{RESUMEN}

El presente texto presenta la entrevista con la Profesora Dra. Terezinha Petrúcia da Nóbrega, realizada el 3 de noviembre de 2017 a las 19:20 en Fortaleza, Ceará. La profesora nos cuenta sobre su trayectoria académica y sus aproximaciones con el pensamiento de la fenomenología de MerleauPonty. Relata sobre algunas de sus obras, y sus experiencias con el autor Bernard Andrieu en la playa de la Tambaba. Por fin nos hace un breve relato sobre su visión acerca de una educación sensible.

Palabras Clave: Cuerpo. Fenomenología. Corporeidad. Entrevista. Petrúcia Nobrega. 


\section{APRESENTAÇÃO}

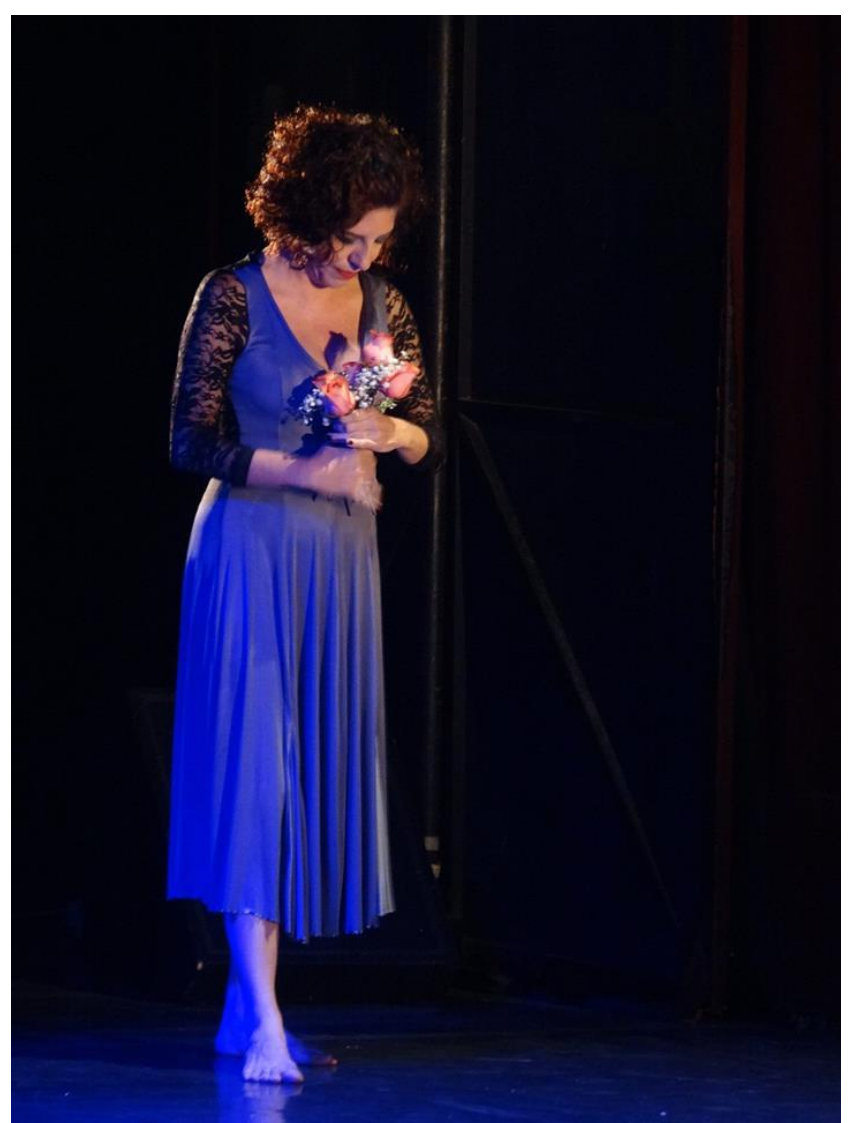

Figura 1: Foto feita em abril de 2014, no espetáculo em homenagem ao professor Edson Claro, dirigido pro Edeilson Matias. Petrucia da Nóbrega dançou, dirigida por Francisco Júnior e com figurino de Carlos Sérgio Borges a coreografia Petrus de Edson Claro (citada na $4^{\circ}$ pergunta da entrevista), e dançou com Margoth Lima.

Professora Dra. Terezinha Petrúcia da Nóbrega é graduada em Educação Física (1989) e em Filosofia (1995) pela Universidade Federal do Rio Grande do Norte (UFRN). Mestre em Educação (1995) pela UFRN e doutora em Educação (1999) pela Universidade Metodista de Piracicaba (UNIMEP). Realizou estágio Pós-Doutoral na Puc/São Paulo (2009), e também na área de filosofia na Université de Montpellier (II e III - 2009 e 2010). Foi professora convidada da Université de Montpellier, Institut de Formation de Maîtres (2011). Realizou estágio de pesquisa Sênior/Pós-Doutoral na École Normale Superieur de Paris (2014-2016). Atualmente é professora titular da UFRN, coordenadora do Grupo de Pesquisa Estesia: corpo, fenomenologia e movimento e do Laboratório Ver - Visibilidades do corpo e da cultura de movimento, Coordenadora e professora do Programa de Pós-Graduação em Educação Física, e professora do Programa de Pós-Graduação em Educação da UFRN. Já organizou 7 livros na área, possui 13 livros escritos e 31 capítulos de livros publicados. Petrucia da Nóbrega é, senão, uma das maiores escritoras sobre o corpo, epistemologia e Merleau-Ponty do Brasil. 


\section{Professora Petrucia da Nóbrega, conte-nos sobre sua trajetória acadêmica e de como você iniciou o diálogo entre a Educação Física e a Filosofia.}

Primeiro eu fiz a formação em Educação Física, na Universidade Federal do rio Grande do Norte (UFRN). E eu me envolvi com a dança também, porque eu não vinha do esporte, era mais ligada a ginástica e a dança. Então, eu encaminhei por essa trajetória. O curso, assim como todos os cursos na época no Brasil, era bastante tecnicista. E nesse campo da dança eu conheci o Edson Claro, que tinha se mudado para Natal e dava aulas de dança na cidade. A partir daí eu comecei a me aproximar da dança, da consciência corporal. Terminei a graduação e fui fazer uma Especialização em Dança, em São Paulo com o Edson Claro. E lá, ao mesmo tempo em que terminei esse curso de graduação em Educação Física e fazendo a especialização em dança, eu fui me dando conta das lacunas na área de Educação Física. E que aquilo intelectualmente não me era suficiente. Então posteriormente eu fiz o reingresso no curso de graduação em Filosofia na UFRN, porque eu sentia que era necessário complementar minha formação acadêmica. E assim o curso de Filosofia abriu um mundo para mim; todas as referências que eu comecei a ler, as questões do próprio pensamento filosófico... E isso me abriu portas. Naquele período, mesmo ainda hoje, não existiam leituras e cursos sobre o corpo, mas eu entrei em contato com a filosofia fenomenológica através de Husserl. Era filosofia contemporânea, eu tive contato com aquele autor e aquilo me interessou. Nessa época foi publicado no Brasil, através da organização do Wagner Moreira, o livro "Educação física \& esportes: Perspectivas para o século XXI" (1992) e eu comprei e li o livro. Porque naquele tempo não tinha internet, era muito difícil você ter acesso a literatura da área. Então eu comprei, acho que num congresso (não lembro muito bem), e li o texto do Santin: "Perspectivas na visão da corporeidade". E aquilo me encantou e eu uni a todo o meu desejo e a necessidade de estudar mais sobre o corpo. Porque eu já vinha da filosofia. E a partir daquilo eu encontrei um caminho, digamos assim, junto com os estudos da consciência corporal que eu já fazia na especialização em dança com o Edson Claro, e com a filosofia foi indo junto. Foi realmente um universo de descoberta! Eu comecei a estudar sozinha MerleauPonty, ir à biblioteca da UFRN. Nela nós tínhamos a obra inteira de Merleau-Ponty em francês e alguns textos em português, na época, português só tinha "Fenomenologia da percepção (1971)" na versão da editora Freitas Bastos, da década de 70. E a obra "A estrutura do comportamento (1975)", que foi publicada em português pela editora Interlivros, de 1974. Eu mergulhei naquilo de uma forma muito solitária, por que não existiam grupos de estudo, era tudo muito difícil. Logo depois eu fiz um Mestrado em Educação na UFRN, trabalhando com essas referências, e já tinha o curso de Filosofia. E o Professor Wagner Way Moreira, que era, então, professor da UNICAMP (Universidade de campinas) e da UNIMEP (Universidade Metodista de Piracicaba), veio para minha banca do mestrado e a partir desse contato eu fui fazer o Doutorado com ele na UNIMEP; onde eu fui me aprofundar também na leitura do Merleau-Ponty e fazer uma relação mais próxima com a educação, porque o doutorado era em educação. E desse momento pra cá, Merleau-Ponty é, e continua sendo minha referência de pensamento principal, não é a única, mas é ela que me possibilita compreender a questão do corpo, do movimento e tem me aberto outras possibilidades. 


\section{Em suas obras é nitidamente perceptível a perspectiva fenomenológica de Merleau- Ponty, fazendo com que suas argumentações ganhem ainda mais destaque. Como vem se dando a articulação deste referencial com a educação física?}

Já se passaram mais de 20 anos. Então eu acho que eu amadureci intelectualmente. Acho que a própria área amadureceu epistemologicamente. E eu vejo que há um terreno mais fértil para a discussão fenomenológica. Principalmente os estudos do corpo cresceram bastante no interior da Educação Física, dos debates. Dentro do Colégio Brasileiro de Ciências do Esporte (CBCE) eu tive a oportunidade de coordenar o grupo de epistemologia, e a gente instaurou o $1^{\circ}$ Congresso Brasileiro de Epistemologia, que nós fizemos em Natal, e o corpo foi um dos elementos bastante discutidos. Posteriormente foram criados outros grupos de trabalhos no CBCE sobre o corpo. Eu acho que a questão do corpo ela hoje é uma questão estabelecida dentro da Educação Física, não só no Brasil como em outros países. É um dos descritores na nossa área a questão do corpo no momento. E a fenomenologia sem dúvida nenhuma contribuiu para isso, assim como o pensamento fenomenológico de autores como Silvino Santin, Wagner Moreira, Elenor Kunz, eu própria, Professor Iraquitan Caminha. Portanto, é um grupo. Inclusive nós (eu junto com o professor Iraquitan Caminha) estamos organizando um livro exatamente sobre Merleau-Ponty e Educação Física, deve sair ano que vem. Justamente onde a gente vai expor e reunir esse movimento em torno do pensamento de Merleau-Ponty especificamente na Educação Física brasileira. Eu vejo que Merleau-Ponty são as noções de corpo próprio, as noções de motricidade, a intencionalidade do movimento, do mover-se, dessa ideia da corporeidade mesmo, devemos ao pensamento de Merleau-Ponty.

\section{Professora você traz em muitas de suas obras as noções dos autores Maturana e Varela, como a enação e a autopoesis. Como você chegou a essas conceitos e como eles encorpam os seus textos?}

Quando eu fiz o Doutorado na UNIMEP em Piracicaba, o meu projeto inicial era exatamente as ideias do corpo em Merleau-Ponty para a educação. Chegando lá eu tive o prazer, a honra de estudar com o professor Hugo Assman, com o professor Francisco Fontenela. Mas o professor Hugo Assman estava nessa época fazendo a leitura do Maturana e Varela. Inclusive o livro era em inglês do Varela "The embodied mind (1991)", e nós lemos esse material. E tanto o Maturana como o Varela apresentavam a fenomenologia e o pensamento de MerleauPonty como bases filosóficas para sua biologia fenomenológica, para fundamentar os conceitos de enação e da autopoiesis. E para mim eram argumentos para defender a perspectiva da corporeidade na educação e esse tema da cognição. Que somente agora mais de 10 anos depois volta à cena com muita força na Educação e na própria Educação Física. E naquela época eu já me interessei por isso, mas não numa perspectiva mentalista ou cognitivista, mas numa perspectiva fenomenológica de que o cérebro também é corpo. E que as funções mentais não se separam da corporeidade, ao contrário, elas emergem da corporeidade e que ainda há um resquício e um paralelismo psicofísico, do positivismo em algumas perspectivas sobre a mente e o cérebro atualmente. Eu me afasto desde o início dessa 
perspectiva positivista de análise sobre o cérebro e a cognição, para me filiar, justamente, me aproximar aos estudos de Maturana e Varela. A partir dos quais, a gente pode afirmar que a cognição emerge da corporeidade e que a cognição não é somente um processamento de informações, gestuais e cognitivos, mas tem também a emoção e a percepção que, também, estão envolvidas nesse processo.

\section{Conte-nos sobre a obra publicada em 2015 "Sentir a dança ou quando o corpo se põe a dançar... (2015)", e sobre os sentidos estéticos e estésicos que você traz sobre a dança e as artes.}

Me dá assim, uma emoção mesmo de falar sobre isso, porque esse livro ele condensa uma trajetória. Esse livro é fruto do meu estágio sênior. Foi o momento onde eu pude sistematizar esse meu referencial fenomenológico, especialmente a fenomenologia de Merleau-Ponty. Mas aprofundá-lo e reencontrar a dança, que é algo que está na minha história de formação, fui dançarina, criadora de grupo de dança na universidade, orientei muitos trabalhos sobre dança, o meu concurso para entrar no departamento de Educação Física (DEF-UFRN) foi para a área de dança. Mas eu nunca havia feito uma pesquisa sobre dança. Mas nesse estágio sênior, na École Normale Superieur de Paris que durou dois anos no departamento de Filosofia, eu trabalhei com a professora Claude Imbert, minha supervisora. E ela me impulsionou a entrar na dança, a retomar esse meu contato com a dança. E dizendo assim: "não você tem todo esse conhecimento de Merleau-Ponty". E Merleau-Ponty também trabalhou muito sobre a cultura, o cinema, a literatura e sobre artes em geral que são também minhas paixões. Mas ele pouco falou sobre a dança. Tem apenas uma nota na obra "Fenomenologia da percepção" na qual ele se refere sobre a dança. E eu digo, inclusive nesse livro, que é a dança moderna e todas as características que ele descreve. Então ela disse: "Mas é você que tem que falar sobre a dança. Você vai agora...". E eu resisti a essa ideia, porque eu já estava mais afastada da dança, e mais envolvida com a literatura, com o próprio cinema, coordenando um projeto sobre o cinema. Mas fui aos pouquinhos retomando esse meu encantamento sobre a dança. Por ter morado em Paris, morei 2 anos de 2014 a 2016, isso me possibilitou o contato com espetáculos, com esse movimento da dança mesmo. E eu fui me reencantando e nesse processo eu também voltei a dançar em homenagem, justamente, a Edson claro, que faleceu em 2013. E ele tinha feito um solo que chama-se Petrus para mim dançar. Mas na época eu recusei, porque eu estava justamente envolvida com a coordenação de pós-graduação, e não estava dançando. Não me via no palco de novo, 20 anos depois. Mas quando ele faleceu e nós organizamos em Natal um homenagem a ele em 2014, pois ele faleceu no final de 2013, e essa homenagem foi em abril de 2014, eu senti vontade de dançar! Porque eu não tinha mais esse desejo de dançar, de ir pra um palco e dançar não. E também não tenho mais, eu só fiz em homenagem a ele. A dança está em mim, mas eu não tenho mais a necessidade, o desejo de dançar, de estar num palco com as pessoas me vendo dançar. Mas eu sempre gostei de espetáculos de dança, e eu escolhi escrever sobre isso nesse livro, que é fruto do meu estágio sênior. E nele eu faço um aprofundamento da leitura que eu tinha de Merleau-Ponty, justamente colocando em cena essas noções de estesiologia e de expressão. Que são noções 
que ele trabalhou justamente no primeiro e nos últimos cursos que ele deu no Collège de France. E para dizer que corpo não é apenas essa descrição perceptiva do corpo e do sistema corporal, mas ele vai aprofundar essas noções de corpo na sua obra a partir dessa noção de corpo estesiológico, desse corpo que sente. Mas não se trata apenas do sentir como um estilo sensorial, mas um sentir ligado ao desejo, ao simbólico e as emoções. Então, ele faz uma relação com a psicanálise, também, para dizer dessa experiência do corpo que é também, como ele diz, uma fisionomia os afetos. E isso se dá a ver na expressão, na comunicação do corpo, através da expressão, da postura, da comunicação do corpo, da cultura, da consciência corporal e obviamente da linguagem. E nessa obra eu relaciono isso com a dança.

\section{Ultimamente há muitas publicações suas com o autor Bernard Andrieu, sobre o método imersivo, a ecologia do corpo e as suas experiências na praia da Tambaba. Conte-nos sobre esses conceitos e sobre esta experiência.}

Bernard é um parceiro! Temos essa partilha de uma vida filosófica. Eu conheci Bernard em 2009, em Paris, quando fui pra universidade de Montpellier, num evento. Ele ficou sabendo que eu estudava Merleau-Ponty e me convida para escrever um texto para o centenário do Merleau-Ponty. E aí começou essa parceria intelectual que se aprofundou e se transformou quando eu fui morar em Paris em 2014. E nesse momento Bernard começava a desenvolver a emersiologia. Eu trabalhando com estesiologia e ele trabalhando com a emersiologia (os sentidos que nascem no corpo). Mas ele insere também essa emersiologia, no aspecto que me interessou muito, foi da ecologia do corpo. Eu me encantei com essa ideia da ecologia corporal como um estilo de vida. Um estilo de vida, de ser, quer dizer, não apenas ligada a uma epistemologia, mas ligada a uma épica, a uma prática de vida. E nós começamos a trabalhar juntos. Temos um projeto que se chama Somaticians, que é uma cartografia. Como eu fazia uma cartografia da dança, nós tivemos uma ideia de fazer uma cartografia. Uma cartografia dos pioneiros da cultura corporal, dos estudos do corpo, da corporeidade. Sejam psicólogos, historiadores, professores de Educação Física, psicanalistas, médicos, enfim. Temos um site que é o Somaticians ${ }^{1}$. E publicamos um livro ano passado. O Bernard tem 4 livros sobre ecologia corporal. E em 2015 ele esteve em Natal, e nós fomos a Tambaba ${ }^{2}$, que eu já conhecia. E a partir dali nós começamos a fazer esses estudos do naturismo como um exemplo de ecologia corporal no Brasil. Nós, então, escrevemos sobre isso e publicamos. E eu tenho desenvolvido essa ideia, que é dele, da ecologia corporal. Mas acho que o Brasil é propício a essa ideia pela natureza, e ao mesmo tempo eu considero como um tabu a ecologia corporal. E como algo que pode exemplificar a compreensão do Merleau-Ponty sobre a natureza. Uma natureza que não está apenas fora de nós, mas que está incorporada, também, em nós, através desse contato com a natureza. E nós escrevemos sobre o naturismo, escrevemos sobre a questão do bronzeamento, que deve ser inclusive publicada agora no final do ano. Enfim, toda essa ideia de uma filosofia do corpo ampliada em relação com a natureza, e das práticas corporais com a natureza.

\footnotetext{
${ }^{1}$ http://somaticiens.com/

${ }^{2}$ Tambaba é uma praia brasileira localizada no município de Conde, na Paraíba, sendo uma área naturista. Conexões: Educ. Fís., Esporte e Saúde, Campinas: SP, v. 16, n 2, p. 240-248, abr./jun. 2018. ISSN: 1980-9030
} 


\section{Sobre a obra "Corporeidade e Educação física: do corpo-objeto ao corpo-sujeito" (publicado no de 2000 e esgotada, tem previsão de quando teremos uma próxima edição?}

Nossa, essa obra ela foi publicada em 2000, mas ela é fruto da dissertação do Mestrado em Educação, que eu concluí em 1995. Cinco anos depois eu consegui publicar pela editora da UFRN, a primeira edição, temos depois a segunda edição, a terceira edição esgotada em 2009. É uma obra que já tem quase 18 anos, já quase em sua maioridade. Eu tenho planos de publicar sim, inclusive estou vendo com a própria editora da UFRN. Pretendo fazer uma edição ampliada, revisada. E pensar pra 2018, o mais tardar 2019, quando a primeira edição completará praticamente aí seus 20 anos. Em 2020 ela completa seus 20 anos de obra. Então até $2020 \ldots$

\section{Professora, por fim, na sua visão qual o desafio da Educação Física para uma educação sensível?}

Eu penso muitas coisas sobre isso. Eu acho que uma educação sensível é aquela que é capaz de mobilizar o outro através dessa noção de intercorporeidade. Não é apenas o sujeito individual, mas é um sujeito em contato com o outro. É o outro, é o alguém da vida, da cultura, é o outro humano, a alteridade, é o alheio ao estrangeiro. A educação sensível é você estar disponível a essa intercorporeidade. Acho que a educação sensível não é uma prerrogativa da Educação Física, acho que ela é mais ampla. E ela não se dá só na escola. Ela se dá no cinema, no teatro, na vida, nas experiências pessoais, nas experiências afetivas. Acho que é mais ampla. Uma educação que nos sensibiliza para esse estar vivo, estar no mundo em contato com o outro. A Educação Física assim como outras disciplinas do currículo escolar pode contribuir. Mas a educação sensível é algo em si que ultrapassa o currículo escolar.

\section{REFERENCIAS}

MERLEAU-PONTY, M. A estrutura do comportamento. Belo Horizonte: Interlivros, 1975.

MERLEAU-PONTY, M. Fenomenologia da percepção. Rio de Janeiro: Freitas Bastos, 1971.

MOREIRA, Wagner Way. (Org.). Educação física \& esportes: perspectivas para o século XXI. Campinas: Papirus, 1992.

NÓBREGA, Terezinha Petrucia da. Corporeidade e educação física: do corpo objeto ao corpo-sujeito. Natal: Ed. da UFRN. 2000. 
NÓBREGA, Terezinha Petrucia da. Sentir a dança ou quando o corpo se põe a dançar.... Natal: Ed. da UFRN, 2015.

VARELA, Francisco; THOMPSON Evan; ROSCH, Eleonor. The embodied mind: cognitive science and human experience. Cambridge: MIT Press, 1991. 